\title{
Urinary prostasin in humans: relationships among prostasin, aldosterone and epithelial sodium channel activity
}

\author{
Aya Koda ${ }^{1}$, Naoki Wakida ${ }^{2}$, Kazuhiro Toriyama ${ }^{1}$, Kazutoshi Yamamoto ${ }^{3}$, Hiromi Iijima ${ }^{4}$, Kimio Tomita ${ }^{2}$ and \\ Kenichiro Kitamura ${ }^{2}$
}

Prostasin, a membrane-bound serine protease, is known to increase the activity of the epithelial sodium channel (ENaC). Gene expression of prostasin was shown to be regulated by aldosterone, which increases the rate of sodium reabsorption through ENaC. To clarify the physiological relationships among prostasin, aldosterone and $\mathrm{ENaC}$, we developed a specific radioimmunoassay (RIA) for human prostasin. Prostasin levels in urine were determined in 26 normotensive and 121 hypertensive subjects. Aldosterone content in urine and plasma, urinary $\mathrm{Na} / \mathrm{K}$ ratio and other clinical parameters were also measured. We observed a highly significant correlation between prostasin and aldosterone concentration in urine (correlation coefficient: $0.673, P<0.0001$ ). A significant correlation was also found between urinary prostasin and plasma aldosterone concentration (correlation coefficient: $0.229, P<0.05$ ). In addition, urinary prostasin excretion was inversely correlated with urinary Na/K ratio (correlation coefficient: $-0.425, P<0.0001$ ). In conclusion, we developed a prostasin-specific RIA and applied it to the clinical study. Our findings suggest that urinary prostasin level is strongly correlated with urinary or plasma aldosterone level and may serve as a surrogate marker for ENaC activation in hypertensive patients. However, it is not clear, at the present time, whether endogenous aldosterone regulates prostasin expression or vice versa.

Hypertension Research (2009) 32, 276-281; doi:10.1038/hr.2009.6; published online 27 February 2009

Keywords: aldosterone; epithelial sodium channel; prostasin

\section{INTRODUCTION}

Aldosterone, a principal human mineralocorticoid hormone, is well known as the primary hormone that regulates salt balance, extracellular fluid volume and blood pressure (BP). ${ }^{1-3}$ It has also been reported that aldosterone enhances the rate of sodium reabsorption across epithelial cells of the distal nephron by increasing sodium transport through the epithelial sodium channel (ENaC), a principal physiological target of aldosterone, ${ }^{4,5}$ consisting of three homologous subunits $(\alpha, \beta$ and $\gamma){ }^{6,7}$

In 1997, Vallet et al. ${ }^{8}$ identified a novel mechanism for the local regulation of $\mathrm{ENaC}$ activity. They cloned a trypsin family serine protease, xCAP1 (channel-activating protease 1), from a Xenopus kidney epithelial cell line (A6), by using a functional complementation assay designed to detect activators of $\mathrm{ENaC}$ in the Xenopus oocyte expression system. In this assay, they showed a two- to threefold activation of $\mathrm{ENaC}$ when $\mathrm{xCAP} 1$ was coexpressed with rat or Xenopus $\mathrm{ENaC}$ in oocytes. This effect is thought to rely on extracellular xCAP1 protease activity, as exposure of the apical membrane to the protease inhibitor aprotinin reduced amiloride-sensitive sodium transport. The first mammalian homologue of xCAP1, mouse CAP1 (mCAP1), was isolated from a mouse cortical collecting duct cell line. ${ }^{9}$ Vuagniaux et al. ${ }^{9}$ suggested that CAP1 is an orthologous gene for prostasin, and also showed that mCAP1 increases amiloride-sensitive sodium currents when coexpressed with $\mathrm{ENaC}$ in Xenopus oocytes.

Prostasin, a serine protease originally purified from human seminal fluid, ${ }^{10-12}$ is synthesized with a glycosylphosphatidylinositol membrane anchor and can also be secreted into physiological fluids. ${ }^{13}$ This protein is abundantly present in the seminal fluid, urine and prostate gland, and it is also present at moderate levels in the kidney, bladder, lung, colon, pancreas, salivary gland, bronchi, liver and endometrium. ${ }^{10,11,14-16}$ Prostasin has been identified as a potential regulator of amiloride-sensitive $\mathrm{ENaC}$ function in the kidney, lung and airways. ${ }^{17-23}$ However, the physiological role of this protein remains largely undetermined, although dysregulation of prostasin expression has been found in high-grade human prostate and breast cancers. ${ }^{14,24-26}$ Catalytically active prostasin was detected in urine from both men and women. ${ }^{10}$ Although the concentration of prostasin in urine is lower than that in seminal fluid, the production of prostasin has to be very active in the kidney, considering the relatively large amount of the urine excreted in a day. These facts suggest the possibility that 
prostasin may play a key role in the regulation of renal tubular sodium transport by an autocrine and/or paracrine mechanism.

Recently, we also showed that rat CAP1/prostasin activates $\mathrm{ENaC}$ when the two are coexpressed in Xenopus oocytes, and that aldosterone substantially increases prostasin expression with functional consequences on sodium balance in vivo. ${ }^{27}$ Furthermore, we showed that urinary excretion of prostasin in patients with primary aldosteronism was substantially elevated and normalized after adrenalectomy. ${ }^{19}$ Regarding urinary prostasin, Olivieri et al. ${ }^{20}$ showed that spironolactone increased the urinary $\mathrm{Na} / \mathrm{K}$ ratio and decreased urinary prostasin level in normotensives in whom the renin-aldosterone axis was activated by a low sodium intake, suggesting the regulation of urinary prostasin by aldosterone. On the contrary, however, one report presented evidence that the expression of prostasin by adenovirus-mediated human prostasin gene delivery resulted in a subsequent increase in aldosterone production and hypertension in rats. ${ }^{28}$ $\mathrm{BP}$ increase was accompanied by elevated plasma aldosterone after prostasin gene transfer, before the development of hypertension, indicating that stimulation of aldosterone production is the primary target of prostasin. Accordingly, it is unclear whether aldosterone increases prostasin expression or, on the contrary, if preceding stimulation of prostasin leads to the release of aldosterone from adrenal gland. To determine the role of prostasin in the pathophysiology of hypertension or hyperaldosteronism, it is important to develop a prostasin-specific and high-sensitive assay method. Therefore, in this article, we describe the development of a specific radioimmunoassay (RIA) for human prostasin and its application to the evaluation of prostasin levels in urine from normotensive and hypertensive subjects. The physiological relationships among prostasin, BP, aldosterone and $\mathrm{ENaC}$ function were analyzed and discussed.

\section{METHODS}

\section{Purification of recombinant human prostasin}

A cDNA for recombinant human prostasin was created by inserting an enterokinase cleavage site, Asp-Asp-Asp-Asp-Lys, between the light chain and heavy chain and by replacing the C-terminal membrane anchoring domain with a $6 \times$ His tag, so that the recombinant protein could be secreted as a proprotein and could be activated by exogenous enterokinase treatment. The cDNA was subcloned into the transfer vector pM00001 (Katakura Industries, Saitama, Japan). Linearized hybrid baculovirus DNA 'Bac-Duo' (Katakura Industries) was co-transfected with the recombinant plasmid into a Spodoptera frugiperda cell line SF21AE. Three days after transfection, the culture supernatants containing recombinant human prostasin virus were harvested and subjected to the standard plaque purification methods. Silkworm larvae at the early stage of the fifth-instar were infected with $9 \times 10^{4}$ plaque-forming units (PFU) of recombinant virus. On the fifth day after infection, hemolymph containing recombinant human prostasin was harvested by cutting off several abdominal legs from each larva. The hemolymph was collected in $0.1 \mathrm{~m}$ phosphate buffer $(\mathrm{PB}), \mathrm{pH} 6.8$ supplemented with $0.1 \% \mathrm{~N}$-phenylthiourea. Recombinant human prostasin was purified using a Ni-sepharose column (HisTrap HP: GE Healthcare Bio-Sciences, Piscataway, NJ, USA) and an ionexchange column (Resource Q: GE Healthcare Bio-Sciences) with an AKTA prime system (GE Healthcare Bio-Sciences). Purified recombinant prostasin was incubated with enterokinase (EK Max: Invitrogen, Carlsbad, CA, USA) for $16 \mathrm{~h}$ at $37^{\circ} \mathrm{C}$ to generate an enzymatically active recombinant human prostasin by cleaving the enterokinase cleavage site between the light and heavy chains. Sixteen hours after incubation, enterokinase was removed from the reaction mixture by using an enterokinase removal kit (Sigma, St Louis, MO, USA). Enzymatic activity of prostasin was assessed by an assay using a synthetic substrate, N-t-Boc-Gln-Ala-Arg-7-amido-4-methyl coumarin (QAR-MCA). Application of the active recombinant prostasin significantly increased the $\mathrm{ENaC}$ activity in Xenopus oocytes, indicating the reliability of this recombinant protein (data not shown).

\section{Production of antiserum}

For antibody production, a partial sequence of peptide ${ }_{(102-120)}$ of human prostasin, AHQLDSYSEDAKVSTLKDI, was synthesized as an octa-branching multiple antigenic peptide (Peptide Institute, Osaka, Japan) consisting of a core matrix made up of three levels of lysine and eight amino termini for anchoring peptide antigens. ${ }^{29}$ Antiserum against a synthetic prostasin peptide was generated in a rabbit by means of the lymph node injection technique. ${ }^{30}$ For immunization, $100 \mu \mathrm{g}$ of multiple antigenic peptide was dissolved in $100 \mu \mathrm{l}$ of saline, emulsified with an equal volume of Freund's complete adjuvant (Dibco, Detroit, MI, USA), and injected into the popliteal lymph nodes. Starting 2 weeks after the first injection, four subcutaneous injections (100 $\mu \mathrm{g}$ each) were given at multiple sites on the dorsal surface of the rabbit every 2 weeks. Blood was collected from the marginal ear vein every week, starting after subcutaneous injections had begun, and tested for antibody titer by enzyme-linked immunosorbent assay. Two weeks after the last injection, the rabbit was bled from the carotid artery. The serum was separated by centrifugation and stored at $-80^{\circ} \mathrm{C}$. Before use, the antiserum was purified with a synthetic human prostasin peptide-conjugated affinity column (Affi-Gel; Bio-Rad Laboratories, Hercules, CA, USA), and the obtained antibody solution was neutralized, lyophilized and reconstructed to the volume of starting material with $0.01 \mathrm{M}$ PB. The generated antibody did not show any cross-reactivity with renin, angiotensin-converting enzyme, kallikrein, prostaglandins and steroids (data not shown).

\section{Radioiodination of human prostasin peptide}

For use as a radioligand, human prostasin peptide consisting of 19 amino-acid residues was synthesized (Peptide Institute). Radioiodination was carried out at room temperature according to the modified lactoperoxidase method, as described previously. ${ }^{31}$ Briefly, $\mathrm{Na}^{125} \mathrm{I}(7.4 \mathrm{MBq}$, carrier free; GE Healthcare Bio-Sciences) in $2 \mu \mathrm{l}$ of $0.1 \mathrm{~N} \mathrm{NaOH}$ was added to an eppendorf tube containing $25 \mu \mathrm{l}$ of $0.5 \mathrm{M}$ PB (pH 6.9), $2.5 \mu \mathrm{g}$ prostasin peptide in $10 \mu \mathrm{l}$ of $0.05 \mathrm{M} \mathrm{PB}(\mathrm{pH}$ 7.3 ) and 500 ng lactoperoxidase (Sigma) in $5 \mu$ of distilled water. The reaction was started by adding $10 \mu \mathrm{l}$ of $0.00025 \% \mathrm{H}_{2} \mathrm{O}_{2}$. To maintain the reaction, $10 \mu \mathrm{l}$ $\mathrm{H}_{2} \mathrm{O}_{2}$ was added after 1,3 and $6 \mathrm{~min}$. After $10 \mathrm{~min}$ of reaction, the reaction mixture was applied to a Sephadex G10 (GE Healthcare Bio-Sciences) column $(12 \times 0.6 \mathrm{~cm})$ that had been washed with $2 \mathrm{ml}$ of $1 \%$ bovine serum albumin (BSA; Sigma) in $0.05 \mathrm{M} \mathrm{PB} \mathrm{(pH} \mathrm{7.3)} \mathrm{and} \mathrm{equilibrated} \mathrm{with} 0.05 \mathrm{~m} \mathrm{~PB} \mathrm{(pH} \mathrm{7.3).}$ Four hundred microliter aliquots were collected in tubes containing $200 \mu \mathrm{l}$ of $1 \%$ BSA-PBS (phosphate-buffer saline) $(0.01 \mathrm{~m} \mathrm{~PB}$ containing $0.14 \mathrm{M} \mathrm{NaCl}, 1 \%$ BSA and $0.1 \% \mathrm{NaN}_{3}, \mathrm{pH} 7.5$ ). The radioactivity of each fraction was counted in an Aloka gamma counter (AccuFLEX- $\gamma$; Aloka, Tokyo, Japan).

\section{Radioimmunoassay procedure}

In this RIA system, recombinant human prostasin was used as a reference standard. RIA was performed using a double-antibody method. The prostasin antiserum diluted 1:1000 exhibited the ability to specifically bind $22 \%$ of added radioligand in the absence of any unlabeled recombinant prostasin, when $100 \mu \mathrm{l}$ of diluted antiserum and $100 \mu \mathrm{l}$ of labeled prostasin peptide $(10000 \mathrm{cpm})$ were added to each assay tube containing $300 \mu \mathrm{l}$ of $1 \%$ BSA-PBS. This dilution (final dilution 1:5000) was used throughout the experiments. The RIA was carried out in disposable polystyrene tubes $(10 \times 50 \mathrm{~mm}$ evergreen; Evergreen Scientific, Los Angeles, CA, USA). The reference standard or test sample was serially diluted with the assay buffer (1\% BSA-PBS, pH 7.5) and then added to assay tubes containing $200 \mu \mathrm{l}$ of assay buffer in $100-\mu \mathrm{l}$ volumes. The antiserum was diluted 1:1000 with $0.05 \mathrm{~m}$ EDTA-PBS ( $\mathrm{pH} 7.5$ ) containing $1 \%$ normal rabbit serum. One hundred microliters of diluted antibody and $100 \mu \mathrm{l}$ of labeled prostasin peptide diluted with assay buffer were added to each tube in a total volume of $500 \mu \mathrm{l}$. Each preparation was assayed in duplicate. All assay tubes were incubated for $24 \mathrm{~h}$ at room temperature. After incubation, the immune complexes were precipitated by the addition of $200 \mu \mathrm{l}$ of 1:100 dilution of goat anti-rabbit IgG serum (Shibayagi, Gunma, Japan) in $0.05 \mathrm{M}$ EDTA-PBS containing 3.2\% polyethylene glycol 6000 . After incubation for $24 \mathrm{~h}$ at room temperature, each tube was centrifuged at $4{ }^{\circ} \mathrm{C}$ for $30 \mathrm{~min}$ at 3500 r.p.m., and the supernatant was aspirated. The radioactivity in each precipitate was counted in a gamma counter (Aloka). The radioactivity in tubes containing antibody and labeled prostasin peptide but no unlabeled prostasin was 
Table 1 Patient characteristics

\begin{tabular}{|c|c|}
\hline Age (year) & 20-86 (mean: 57.9) \\
\hline Male/female $(n)$ & $66: 81$ \\
\hline Systolic blood pressure $(\mathrm{mm} \mathrm{Hg})$ & $138.9 \pm 2.3$ \\
\hline Diastolic blood pressure $(\mathrm{mm} \mathrm{Hg})$ & $80.9 \pm 1.3$ \\
\hline Heart rate (beats $\mathrm{min}^{-1}$ ) & $73.5 \pm 1.0$ \\
\hline Serum creatinine (mg per $100 \mathrm{ml}$ ) & $1.3 \pm 0.1$ \\
\hline Serum $\mathrm{Na}$ (mequiv. $\mathrm{I}^{-1}$ ) & $140.8 \pm 0.5$ \\
\hline Serum K (mequiv. $\mathrm{I}^{-1}$ ) & $4.3 \pm 0.1$ \\
\hline Serum $\mathrm{Cl}$ (mequiv. $\mathrm{I}^{-1}$ ) & $106.6 \pm 0.3$ \\
\hline Plasma aldosterone concentration $\left(\mathrm{pg} \mathrm{ml}^{-1}\right)$ & $85.3 \pm 5.3$ \\
\hline Plasma renin activity $\left(\mathrm{ng} \mathrm{ml}^{-1} \mathrm{~h}^{-1}\right)$ & $2.6 \pm 0.4$ \\
\hline Plasma cortisol (pg ml-1) & $12.7 \pm 5.6$ \\
\hline Urinary $\mathrm{Na}$ (mequiv. $\mathrm{I}^{-1}$ ) & $106.4 \pm 0.5 .3$ \\
\hline Urinary $\mathrm{K}$ (mequiv. $\mathrm{I}^{-1}$ ) & $35.1 \pm 0.2 .7$ \\
\hline Urinary $\mathrm{Cl}$ (mequiv. $\mathrm{I}^{-1}$ ) & $113.2 \pm 0.6 .6$ \\
\hline Urinary aldosterone $\left(\mathrm{ng} \mathrm{ml}^{-1}\right)$ & $3.9 \pm 0.0 .6$ \\
\hline Urinary albumin $\left(\mathrm{mggCr}^{-1}\right)$ & $281.2 \pm 832.3$ \\
\hline
\end{tabular}

Values are expressed as means \pm s.e. $(n=147)$.

designated $100 \%$, and the counts in the other tubes were expressed as a fraction of this value.

\section{Human subjects}

The protocol used in this study was approved by the institutional review board of Kumamoto University, and informed consent was obtained from all subjects. Twenty-six healthy volunteers, who presented BP $<140 / 90 \mathrm{~mm} \mathrm{Hg}$ and were not on any therapy, were used as a control. Subjects who were already taking antihypertensive therapy or who exhibited systolic BP and diastolic BP of 140 and $90 \mathrm{~mm} \mathrm{Hg}$, respectively, or greater were regarded as hypertensive. Hypertensive subjects with chronic kidney disease (stage 1-4) were also included, and subjects who were taking inhibitors for renin-angiotensin-aldosterone system and diuretics were excluded from our study. As most of the hypertensive subjects were being treated with antihypertensive medication, there were many subjects who exhibited systolic BP/diastolic BP less than 140/90 mm Hg. All subjects were not on salt-restricted diet. Urinary prostasin concentration was examined in 26 normotensive and 121 hypertensive subjects (20-86 years of age; 66 males and 81 females). Blood samples for aldosterone and cortisol, and urine samples for aldosterone, potassium, sodium, albumin and prostasin evaluation were also collected at the same time. These clinical parameters were measured commercially (SRL, Tokyo, Japan), and the results are summarized in Table 1 .

\section{Preparation of urine}

Urine was collected in the morning and immediately chilled on ice. After measuring each urine volume, the $\mathrm{pH}$ was adjusted to 7.0 with $1 \mathrm{~N} \mathrm{NaOH}$; then, complete protease inhibitor cocktail (Roche Diagnostics, Tokyo, Japan) was added to inhibit the activity of endogenous proteases present in the urine. Urine was centrifuged at $4{ }^{\circ} \mathrm{C}$ for $20 \mathrm{~min}$ at 5000 r.p.m., filtrated through a $0.45-$ $\mu \mathrm{m}$ filter (Millipore, Tokyo, Japan), and concentrated by means of Centricon Plus-20 centrifuge filters (molecular weight cutoff 10000 ; Millipore) with the concentration ratio between $1 / 2$ and $1 / 10$. The final volume was accurately measured.

\section{Western blot analysis}

Aliquots of the concentrated urine samples obtained from the human subjects were subjected to SDS-polyacrylamide gel electrophoresis in $10 \%$ polyacrylamide gels. After electrophoresis, proteins were transferred electrophoretically to Immobilon PVDF membranes (Millipore). Membranes were immunostained by the perioxidase-antiperoxidase method using a mouse monoclonal antibody against human prostasin (BD Biosciences, San Jose, CA, USA).

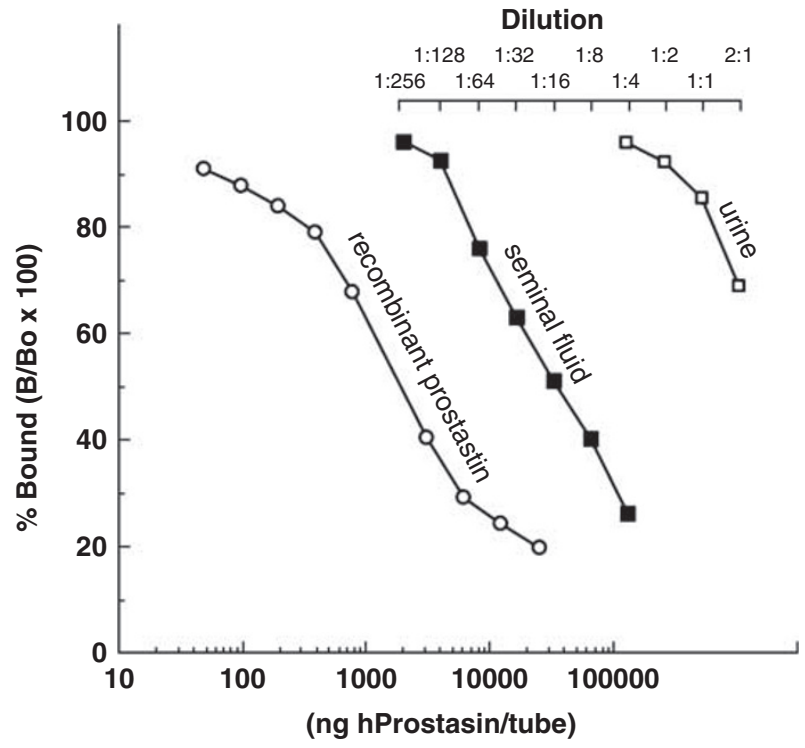

Figure 1 Representative displacement of 125 I-labeled human prostasin peptide with serial dilutions of recombinant human prostasin as a standard, seminal fluid and urine in human. The antiserum against a synthetic prostasin peptide was used at a final concentration of 1:5000. All points are averages of two determinations.

\section{Statistical analysis}

Statistics for linearity, parallelism, precision and potency estimation in the parallel line assay were computed according to the method of Bliss. ${ }^{32}$ Simple correlation coefficients were calculated between urinary prostasin level and plasma aldosterone or urinary aldosterone and $\mathrm{Na} / \mathrm{K}$ ratio in hypertensive patients. The statistical significance of the correlation was evaluated by the method of Snedecor and Cochran. ${ }^{33}$

\section{RESULTS}

A specific RIA for human prostasin was developed by using a synthetic partial peptide of human prostasin for antibody production and radioligand, and a recombinant prostasin as a reference standard. The recombinant human prostasin standard resulted in a log-dose inhibition of binding of ${ }^{125}$ I-labeled prostasin peptide to the antiserum (Figure 1). The sensitivity of the RIA, defined as the amount of recombinant prostasin that significantly decreased the counts by 2 s.d. from the $100 \%$ value, averaged $55.2 \pm 11.0 \mathrm{ng}$ (mean of five assays \pm s.e.) prostasin per $100 \mu$ lof assay buffer. The precision of the assay was determined by assaying the recombinant prostasin standard. The interassay coefficient of variation was $8.2 \%$ when the estimated dose required for $50 \%$ inhibition in five assays was used. The intra-assay coefficient of variation of $1.3 \%$ was obtained by repeated determinations using a 1563-ng recombinant prostasin standard. The linear portions of the inhibition curves obtained using seminal fluid and urine of humans paralleled the linear portion of the inhibition curve obtained with recombinant prostasin (Figure 1). To confirm the reliability of this RIA system, we compared the amount of prostasin in urine determined by the RIA with the abundance of prostasin detected by immunoblotting of the corresponding urine sample. As shown in Figure 2, each immunoassayable prostasin level (Figure 2a) corresponded to that immunoreacted with a monoclonal antibody against human prostasin (Figures $2 \mathrm{~b}$ and $\mathrm{c}$ ).

The RIA was applied to the determination of urinary prostasin in 26 normotensive and 121 hypertensive subjects. Urinary or plasma aldosterone levels, and other major clinical characteristics (Table 1), 


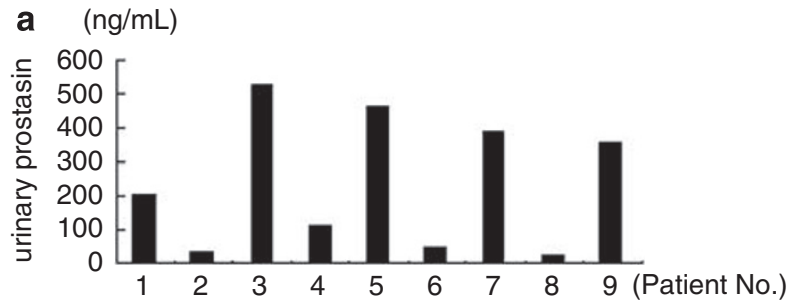

$\begin{array}{lllllllllll}\text { b } & 1 & 2 & 3 & 4 & 5 & 6 & 7 & 8 & 9 & \text { (Patient No.) }\end{array}$

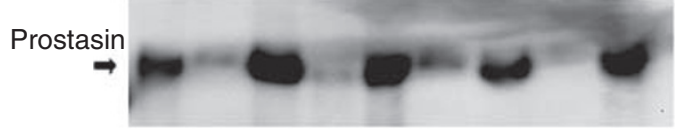

C

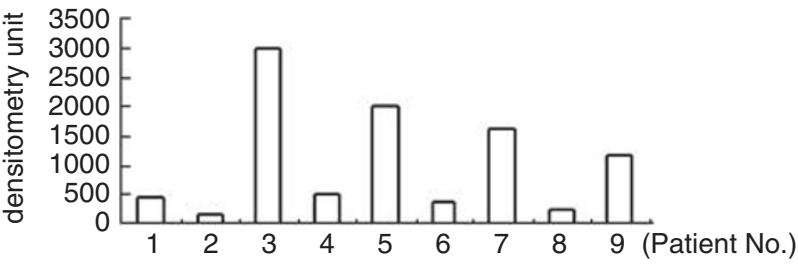

Figure 2 Relationship between radioimmunoassay (RIA) and immunoblotting in the determination of urinary prostasin levels. (a) RIA result, (b) immunoblotting result and (c) intensity of the prostasin band immunoreacted with prostasin antibody.

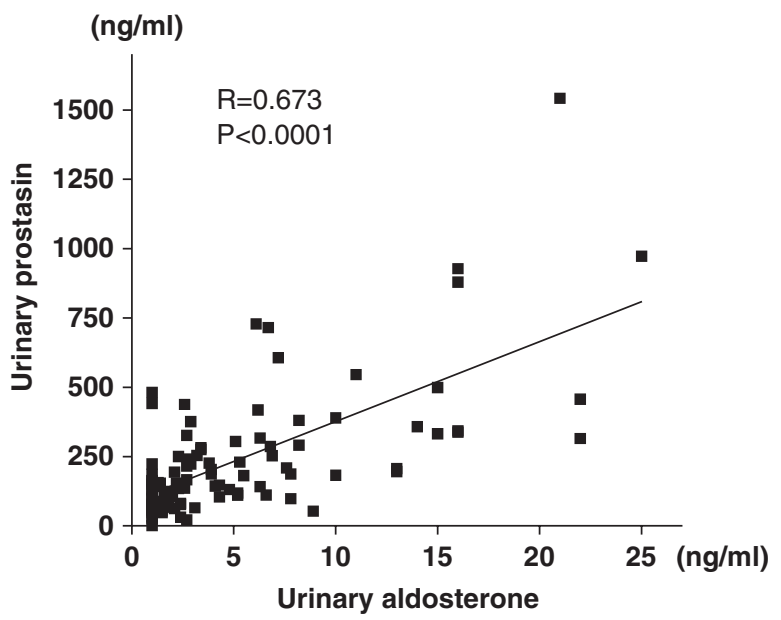

Figure 3 Correlation between prostasin and aldosterone levels in urine. Correlation coefficient is $0.673(P<0.0001)$.

were also evaluated to clarify the physiological relationships among prostasin, aldosterone and $\mathrm{ENaC}$ function. In this study population, the values for urinary prostasin increased as the concentration of urinary aldosterone excretion increased, showing a high significant correlation (correlation coefficient: $0.673 ; P<0.0001$ ) (Figure 3). As shown in Figure 4, moreover, there was a significant correlation between urinary prostasin and plasma aldosterone (correlation coefficient: $0.229 ; P<0.05$ ), whereas plasma cortisol levels did not show any significant correlation with urinary aldosterone levels (correlation coefficient: 0.152 ; not significant (NS)). In addition, urinary prostasin excretion was inversely correlated with urinary $\mathrm{Na} / \mathrm{K}$ ratio (correlation coefficient: $-0.425 ; P<0.0001$ ) (Figure 5 ), and urinary aldosterone

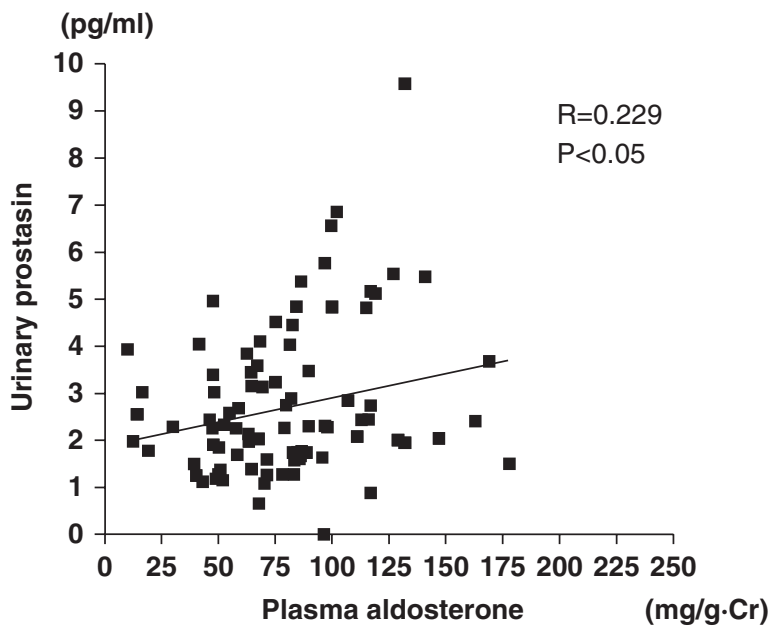

Figure 4 Correlation between urinary prostasin and plasma aldosterone levels. Correlation coefficient is $0.229(P<0.05)$.

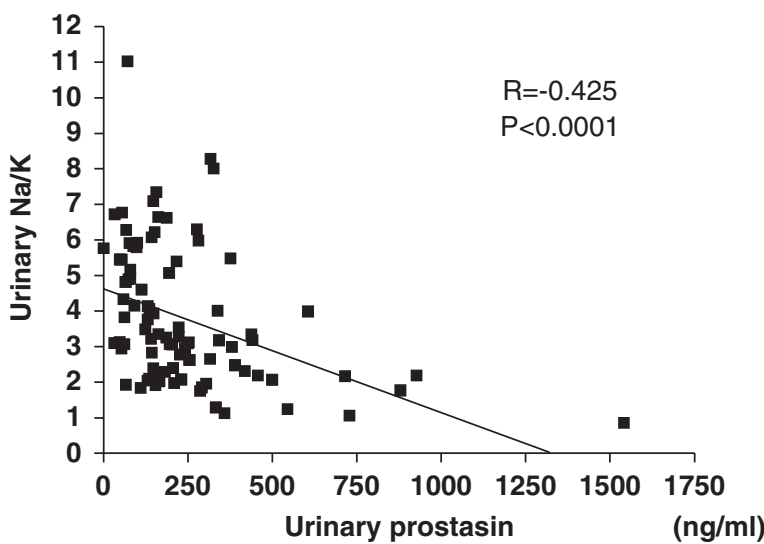

Figure 5 Correlation between prostasin level and $\mathrm{Na} / \mathrm{K}$ ratio in urine. Correlation coefficient is $-0.425(P<0.0001)$

level had a significant negative correlation with urinary $\mathrm{Na} / \mathrm{K}$ ratio (correlation coefficient: $-0.445 ; P<0.0001$ ). We also analyzed the relationships between urinary prostasin and urinary albumin, systolic BP or diastolic BP. However, we did not see any significant correlation within these parameters (correlation coefficient: $0.140,0.028$ and 0.010 , respectively; NS). The ratio of plasma aldosterone to renin activity, ${ }^{34}$ a useful screening test for the diagnosis of primary aldosteronism, was not correlated with urinary prostasin (correlation coefficient: 0.022; NS). Furthermore, renal function that is estimated by the eGFR formula had no effect on either urinary prostasin or urinary aldosterone levels (correlation coefficient: 0.044 and 0.040 , respectively; NS).

\section{DISCUSSION}

This study is the first report of a clinical investigation using an RIA for human prostasin to directly assess urinary prostasin and to determine the relationship between prostasin and aldosterone levels. To date, prostasin has been detected using techniques such as immunohistochemistry and immunoblotting. More recently, Olivieri et al. ${ }^{20}$ established urinary prostasin as a possible candidate marker of $\mathrm{ENaC}$ activation using two-dimensional immunoblotting. The RIA that we developed for the measurement of human prostasin using a partial 
peptide synthesized according to the amino-acid sequence of human prostasin and a recombinant prostasin expressed in silkworm as a radioligand and a reference standard, respectively, was shown to be specific enough to measure urinary prostasin levels. Parallelism of inhibition curves between the recombinant prostasin standard and body fluids such as seminal fluid and urine indicates that the intact form of human prostasin is measurable with this RIA. However, a large amount of prostasin standard was necessary for the displacement of radioligand from the antiserum, suggesting the relatively lower sensitivity of this RIA. Yu et al. ${ }^{10}$ produced an antiserum against prostasin purified from human seminal fluid to develop an RIA for human prostasin. The value of urinary prostasin that we obtained in the present experiment was quite comparable with their value. When the same volume of urine that we used for the RIA was subjected to SDS-polyacrylamide gel electrophoresis and immunoblotting, each level of prostasin estimated with the RIA was reflected in the level of intensity of the prostasin band immunoreacted with monoclonal antibody against human prostasin.

First of all, we analyzed the relationship between prostasin and BP to identify a potential candidate for a novel marker for the pathogenesis of hypertension. In this study, however, we were unable to find an association between BP and prostasin within these samples (data not shown). The reason for this may be derived from the constantly normalized value of BP to less than $140 / 90 \mathrm{~mm} \mathrm{Hg}$ (systolic BP/ diastolic BP; $138.9 \pm 2.3 / 80.9 \pm 1.3 \mathrm{~mm} \mathrm{Hg}$ ) in most of the patients, by virtue of treatment with antihypertensive medications. Antihypertensive drugs, such as Ca channel blockers, may have a direct effect on urinary prostasin levels. Moreover, many of the subjects in this study had multiple complications including diabetes, renal failure and obesity. These metabolic factors may also have an impact on urinary prostasin levels. However, as our study size was not large enough, we were unable to analyze the influence of those drugs or complications on the urinary prostasin level.

We found that urinary prostasin had a highly significant positive correlation with urinary aldosterone levels using the RIA system. A significant positive correlation was also shown between urinary prostasin and plasma aldosterone. To our knowledge, this is the first report showing that an increase in urinary prostasin excretion is concomitant with an increase in urinary or plasma aldosterone. We previously showed the stimulatory effect of aldosterone on the substantial increase in prostasin gene expression and on the accumulation of prostasin in the culture medium of cortical collecting duct cells or urine in the rat, with functional consequences on sodium balance in vivo. ${ }^{19}$ To elucidate the source of the urinary excreted prostasin, we determined the relationship between urinary albumin and urinary prostasin. As described above, we did not detect any significant correlation between them. Therefore, we speculated that major part of the urinary prostasin was produced and secreted by the renal tubules. We also previously showed that urinary excretion of prostasin is increased in aldosterone-infused rat and in patients with primary aldosteronism, and that adrenalectomy in these patients significantly reduces urinary prostasin excretion. Recently, Olivieri et al. ${ }^{20}$ showed that there exists an aldosterone-responsive aliquot in urinary prostasin that is modulated by sodium intake and is potentially suitable as a candidate marker of $\mathrm{ENaC}$ activation. Our present data showing a significant negative correlation (correlation coefficient: $-0.425, P<0.0001$ ) between $\mathrm{Na} / \mathrm{K}$ ratio and prostasin strongly support their observation. A negative correlation between urinary aldosterone level and urinary $\mathrm{Na} / \mathrm{K}$ ratio suggest the cooperative relationship among aldosterone, prostasin and $\mathrm{ENaC}$. Taken together, these findings indicate that prostasin is an important physiological regulator of sodium handling in the kidney, and that aldosterone plays a regulatory role in prostasin expression and urinary sodium and potassium balance. The RIA for urinary prostasin developed by us will be a useful tool for the non-invasive evaluation of ENaC activity in the kidney. As an increased $\mathrm{ENaC}$ activity is involved in some case of salt-sensitive hypertension, the measurement of urinary prostasin levels by this RIA may serve as a diagnostic tool for the salt-sensitive hypertension and for choosing an appropriate therapeutic strategy for hypertension.

In conclusion, we detected prostasin in urine from normotensive and hypertensive subjects by using an RIA for prostasin developed by us. This is the first study to show a link between urinary prostasin and urine or plasma aldosterone in humans. A concomitant increase in urinary prostasin and a decrease in urinary $\mathrm{Na} / \mathrm{K}$ ratio confirm previous findings. Our findings suggest that urinary prostasin may serve as a surrogate marker for $\mathrm{ENaC}$ activation that leads to hypertension. However, it is not clear, at the present time, whether endogenous aldosterone regulates prostasin expression or vice versa. Further study will be required to elucidate this.

\section{ACKNOWLEDGEMENTS}

We thank Drs Hiroyuki Fujisaki (Hirasa Clinic), Shigeru Kiyama (KiyamaNakamura Clinic), Yoshinori Ko (Ko Clinic), Takehiro Ko, Shiho Wakamatsu and Masataka Adachi (Kumamoto University) for sample collection. This work was supported by the following: Grants-in-Aid for Scientific Research from the Ministry of Education, Culture, Sports, Science and Technology in Japan (19590956 to KK and 18390252 to KT); Salt Science Research Foundation Grant (0728 to KK); Mitsubishi Pharma Research Foundation Grant (to KK); and Suzuken Memorial Foundation Grant (to KK).

1 Barbry P, Lazdunski M. Structure and regulation of the amiloride-sensitive epithelial sodium channel. Ion Channels 1996; 4: 115-167.

2 Funder JW. Aldosterone action. Annu Rev Physiol 1993; 55: 115-130.

3 Garty H, Palmer LG. Epithelial sodium channels: function, structure, and regulation. Physiol Rev 1997; 77: 359-396.

4 Rossier BC. 1996 Homer smith award lecture. Cum grano salis: the epithelial sodium channel and the control of blood pressure. J Am Soc Nephrol 1997; 8: 980-992.

5 Verrey F. Early aldosterone action: toward filling the gap between transcription and transport. Am J Physiol 1999; 277 (3 Part 2): F319-F327.

6 Canessa CM, Schild L, Buell G, Thorens B, Gautschi I, Horisberger JD, Rossier BC. Amiloride-sensitive epithelial $\mathrm{Na}+$ channel is made of three homologous subunits. Nature 1994; 367: 463-467.

7 Canessa CM, Horisberger JD, Rossier BC. Epithelial sodium channel related to proteins involved in neurodegeneration. Nature 1993; 361: 467-470.

8 Vallet V, Chraibi A, Gaeggeler HP, Horisberger JD, Rossier BC. An epithelial serine protease activates the amiloride-sensitive sodium channel. Nature 1997; 389: 607-610.

9 Vuagniaux G, Vallet V, Jaeger NF, Pfister C, Bens M, Farman N, Courtois-Coutry N, Vandewalle A, Rossier BC, Hummler E. Activation of the amiloride-sensitive epithelial sodium channel by the serine protease mCAP1 expressed in a mouse cortical collecting duct cell line. J Am Soc Nephrol 2000; 11: 828-834.

$10 \mathrm{Yu}$ JX, Chao L, Chao J. Prostasin is a novel human serine proteinase from seminal fluid. Purification, tissue distribution, and localization in prostate gland. J Biol Chem 1994; 269: 18843-18848.

11 Yu JX, Chao L, Ward DC, Chao J. Structure and chromosomal localization of the human prostasin (PRSS8) gene. Genomics 1996; 32: 334-340.

12 Yu JX, Chao L, Chao J. Molecular cloning, tissue-specific expression, and cellular localization of human prostasin mRNA. J Biol Chem 1995; 270: 13483-13489.

13 Chen LM, Skinner ML, Kauffman SW, Chao J, Chao L, Thaler CD, Chai KX. Prostasin is a glycosylphosphatidylinositol-anchored active serine protease. J Biol Chem 2001; 276: 21434-21442.

14 Chen LM, Hodge GB, Guarda LA, Welch JL, Greenberg NM, Chai KX. Down-regulation of prostasin serine protease: a potential invasion suppressor in prostate cancer. Prostate 2001; 48: 93-103.

15 Chen LM, Wang C, Chen M, Marcello MR, Chao J, Chao L, Chai KX. Prostasin attenuates inducible nitric oxide synthase expression in lipopolysaccharide-induced urinary bladder inflammation. Am J Physiol Renal Physiol 2006; 291: F567-F577. 
16 Lin HY, Zhang H, Yang Q, Wang HX, Wang HM, Chai KX, Chen LM, Zhu C. Expression of prostasin and protease Nexin-1 in rhesus monkey (Macaca mulatta) endometrium and placenta during early pregnancy. J Histochem Cytochem 2006; 54: 1139-1147.

17 Donaldson SH, Hirsh A, Li DC, Holloway G, Chao J, Boucher RC, Gabriel SE. Regulation of the epithelial sodium channel by serine proteases in human airways. $J$ Biol Chem 2002; 277: 8338-8345.

18 Iwashita K, Kitamura K, Narikiyo T, Adachi M, Shiraishi N, Miyoshi T, Nagano J, Tuyen $\mathrm{dG}$, Nonoguchi $\mathrm{H}$, Tomita K. Inhibition of prostasin secretion by serine protease inhibitors in the kidney. J Am Soc Nephrol 2003; 14: 11-16.

19 Narikiyo T, Kitamura K, Adachi M, Miyoshi T, Iwashita K, Shiraishi N, Nonoguchi H, Chen LM, Chai KX, Chao J, Tomita K. Regulation of prostasin by aldosterone in the kidney. J Clin Invest 2002; 109: 401-408.

20 Olivieri O, Castagna A, Guarini P, Chiecchi L, Sabaini G, Pizzolo F, Corrocher R, Righetti PG. Urinary prostasin: a candidate marker of epithelial sodium channel activation in humans. Hypertension 2005; 46: 683-688.

21 Rossier BC. The epithelial sodium channel: activation by membrane-bound serine proteases. Proc Am Thorac Soc 2004; 1: 4-9.

22 Tong Z, Illek B, Bhagwandin VJ, Verghese GM, Caughey GH. Prostasin, a membraneanchored serine peptidase, regulates sodium currents in JME/CF15 cells, a cystic fibrosis airway epithelial cell line. Am J Physiol Lung Cell Mol Physiol 2004; 287: L928-L935.

23 Tuyen DG, Kitamura K, Adachi M, Miyoshi T, Wakida N, Nagano J, Nonoguchi H, Tomita K. Inhibition of prostasin expression by TGF- beta1 in renal epithelial cells. Kidney Int 2005; 67: 193-200.

24 Chen LM, Chai KX. Prostasin serine protease inhibits breast cancer invasiveness and is transcriptionally regulated by promoter DNA methylation. Int J Cancer 2002; 97: 323-329.
25 Chen LM, Zhang X, Chai KX. Regulation of prostasin expression and function in the prostate. Prostate 2004; 59: 1-12.

26 Takahashi S, Suzuki S, Inaguma S, Ikeda Y, Cho YM, Hayashi N, Inoue T, Sugimura Y, Nishiyama N, Fujita T, Chao J, Ushijima T, Shirai T. Down-regulated expression of prostasin in high-grade or hormone-refractory human prostate cancers. Prostate 2003; 54: 187-193.

27 Adachi M, Kitamura K, Miyoshi T, Narikiyo T, Iwashita K, Shiraishi N, Nonoguchi H, Tomita K. Activation of epithelial sodium channels by prostasin in Xenopus oocytes. J Am Soc Nephrol 2001; 12: 1114-1121.

28 Wang C, Chao J, Chao L. Adenovirus-mediated human prostasin gene delivery is linked to increased aldosterone production and hypertension in rats. Am J Physiol Regul Integr Comp Physiol 2003; 284: R1031-R1036.

29 Tam JP. Synthetic peptide vaccine design: synthesis and properties of a high-density multiple antigenic peptide system. Proc Natl Acad Sci 1988; 85: 5409-5413.

30 Goudie RB, Horne $\mathrm{CH}$, Wilkinson PC. A simple method for producing antibody specific to a single selected diffusible antigen. Lancet 1966; 2: 1224-1226.

31 Yamamoto K, Toyoda F, Tanaka S, Hayashi H, Kikuyama S. Radioimmunoassay of a newt sex pheromone, sodefrin, and the influence of hormones on its level in the abdominal gland. Gen Comp Endocrinol 1996; 104: 356-363.

32 Bliss Cl. Statistics in Biology. McGraw-Hill: New York, 1967.

33 Snedecor GW, Cochran WG. Statistical Methods Applied to Experiments in Agriculture and Biology, 7th edn. lowa State Uniersity Press: Ames, 1980.

34 Fogari R, Preti P, Zoppi A, Rinaldi A, Fogari E, Mugellini A. Prevalence of primary aldosteronism among unselected hypertensive patients: a prospective study based on the use of an aldosterone/renin ratio above 25 as a screening test. Hypertens Res 2007; 30: 111-117. 